\title{
Monitoring the Changes of Vegetal Cover of Karblaa Province (Iraq) using Target Detection and Classification Techniques
}

\author{
Israa J. Muhsin', Amjad Hamid² \\ Department of Remote sensing and GIS , College of science, Baghdad University
}

\begin{abstract}
Target detection is the process that helps in determining the changes associated with land use and land cover features with reference to geo-registered multi temporal remote sensing data. This research aimed to utilize change detectionfor investigating the current vegetation cover at(1975-2015) period. The main objectives of this research are collect a number of satellite images in sequence time for the same studied area,these image captured by Landsat (MSS 1975, TM 1985, TM 1995, ETM+ 2005 and Landsat 8 OLI (Operational Land Imager) 2015. Preprocessing such as atmosphere correction and rectification has been done. Gap filling was applied on the defected image (Landsat 2005)to remove slice lines. For monitoring the vegetal changes two classification methods have been used such as support vector machine and K-mean clustering. To detect the target (vegetation) two target detection methods have been applied such as matching filter and Constrained Energy Minimization (CEM). Many histogram and statistical properties were illustrated as well as the pixel count and the target area has been computed.
\end{abstract}

Keywords: support vector machine classifier, matching filter,Constrained Energy Minimization (CEM)

\section{Introduction}

Land-use/land-cover change is an important field in global environmental change research. Inventory and monitoring of land-use/land-cover changes are indispensable aspects for further understanding of change mechanism and modeling the impact of change on the environment and associated ecosystems at different scales. Monitoring of agricultural crop conditions and estimating potential crop yields are important processes for operational programs. Assessment of particularly decreased production caused by a natural disaster, such as drought or pest infestation can be critical for countries or locales where the economy is dependent on the crop harvest [1][2]. Early assessment of yield reductions could avert a disastrous situation and help in strategic planning to meet demands. Change detection is useful in such diverse applications as land use change analysis, monitoring of shifting cultivation, assessment of deforestation, study of changes in vegetation phenology, seasonal changes in pasture production, damage assessment, and crop stress detection, disaster monitoring snow-melt measurements, day/night analysis of thermal characteristics and other environmental changes [3]. The monitoring in this paper has been implemented using classification and change detection techniques, where many preprocessing were applied on the original images such as atmosphere correctionand gap filling after that supervised classification using support vector machine and unsupervised classification using $\mathrm{k}$-mean clustering were employed to classify and isolate the regions of studied area. change detection using target detection using matching filterand Constrained Energy Minimization (CEM)have been performd to detect the change of the vegetation.

\section{Studied Area and Data Gathering}

The main source which was adopted to obtain spectral bands of the studied area was the USGS Global Visualization Viewer of the Earth Resource. Karbala province is the studied areas which enclosed by Path / Row (or Lat $33 \mathrm{~N}^{\circ}$ / Long $44.0 \mathrm{E}^{\circ}$ ). Representing by using Landsat 4-5 Thematic Mapper( TM), Landsat 7 Enhanced Thematic Mapper Plus $\left(\mathrm{ETM}_{+}\right)$and Landsat 8 OLI (Operational Land Imager) sensor onboard satellite, acquire images of the Earth nearly continuously different year from 1975 to 2015 . For more information see table (1). And the series of studied area images since 1975 to 2015 period can be shown in figure (1). An important preprocessing has been performed on sffected image (2005) called gap filling because the $\underline{S}$ can Line Corrector (SLC) [4] which compensates for the forward motion of Landsat-7 has failed on May 31, 2003, and all the subsequent efforts to recover the SLC were not successful. The restoration process shown in figure (1) .

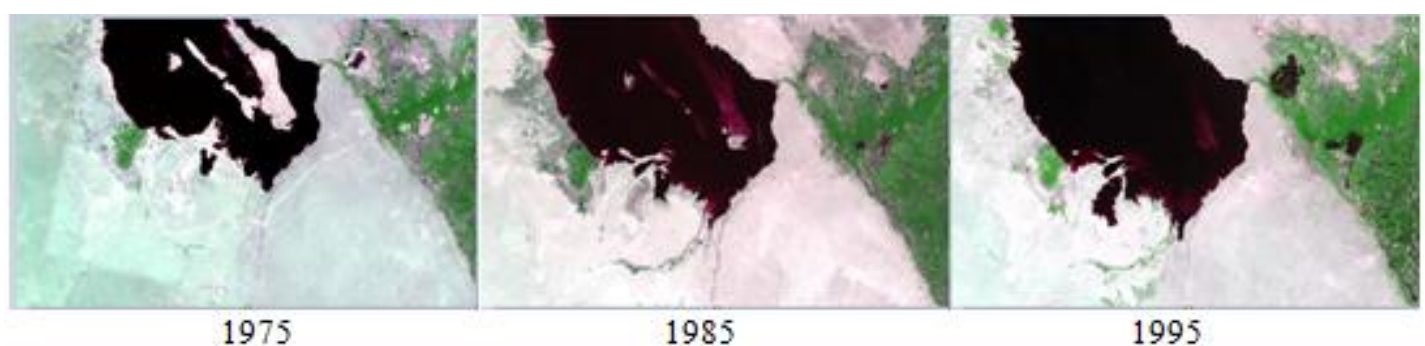

Volume 6 Issue 7, July 2017 www.ijsr.net 
International Journal of Science and Research (IJSR)

ISSN (Online): 2319-7064

Index Copernicus Value (2015): 78.96 | Impact Factor (2015): 6.391

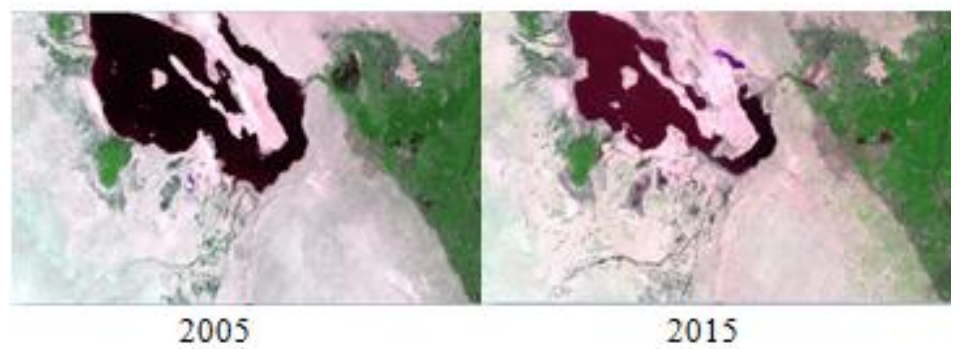

Figure 1: The original of Karbala province images in $(1975,1985,1995,2005,2015)$ period

Table 1: The Landsat and date of captured each original image

\begin{tabular}{|c|c|}
\hline Original images & Source \\
\hline Karbala (1975) & $\begin{array}{c}\text { Landsat 1-5 Multi-Spectral Scanner (MSS) 3- } \\
\text { OCT-1975 }\end{array}$ \\
\hline Karbala (1985) & Landsat 4-5 Thematic Mapper (TM) 9-JAN-1985 \\
\hline Karbala (1995) & Landsat 4-5 Thematic Mapper (TM) 16-JUL-199 \\
\hline Karbala (2005) & $\begin{array}{c}\text { Landsat 7 Enhanced Thematic Mapper Plus } \\
\text { (ETM+) Scan Line Corrector off (SLC-Off) } \\
\text { 2003-present , 24-NOV-2005 }\end{array}$ \\
\hline Karbala (2015) & $\begin{array}{c}\text { Landsat 8 OLI (Operational Land Imager) and } \\
\text { TIRS (Thermal Infrared Sensor), 28-NOV-2005 }\end{array}$ \\
\hline
\end{tabular}

\section{Methodology}

This research involves data acquisition and data preprocessing. Where preprocessing involves radiometric and geometric corrections.In general, radiometric correction is a prerequisite for generating high-quality scientific data, making it possible to discriminate between product artifacts and real changes in Earth processes as well as accurately produce land cover maps and detect changes. Atmospheric corrections for multi-temporal optical satellite images are necessary, especially in change detection analyses. Preprocessing also include restoration of defect image such as 2005 image, where gap filling method has been implemented on the fault image to remove the line in it. The methodology includes many images processing such as image classification, change detection.

\section{Image Classification}

Image Classification has the overall objective to automatically categorize all pixels in an image into classes or themes. The Spectral pattern, or signature of surface materials belonging to a class or theme determines an assignment to a class. There are two types of classification supervised andunsupervised classification.In this research supervised based on support vector machine classifier (SVM) has been adopted to classify the image [5-9], where Regions of interest for each object ofthe studied area have been selected to provide the classes of each image, where each image represent a specified period of the Karbala age has been classified in to five classes; water, urban, soil, vegetation, desert (blue,reed,cyan, green, yellow) the results of apply classification techniques can be shown in figures (2).This research also include k-meanunsupervised classification which can be defined as a means by which pixels in an image are specified to spectral classes without the employer having prior knowledge of the presence or names of those classes. It is performed most often using clustering methods. These procedures can be used to define for each pixel the spectral class and to define the location and number of the spectral classes where the data locates, the results of applying k-mean clustering can be shown in figure (3).The statistical distribution of vegetation class can be shown in figure (4) and figure (5) respectively.

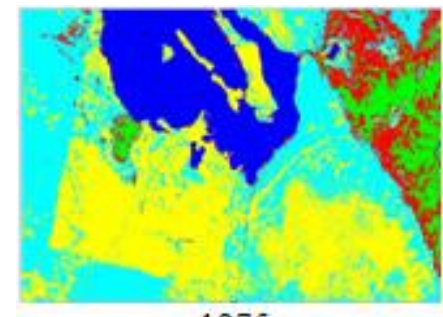

1975

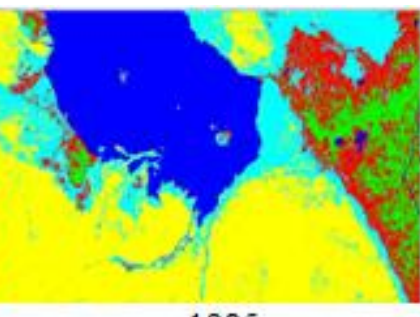

1985

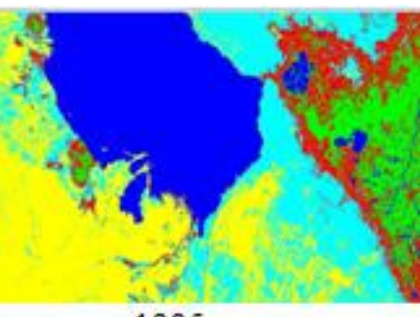

1995

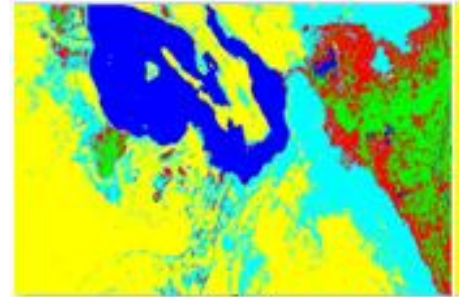

2005

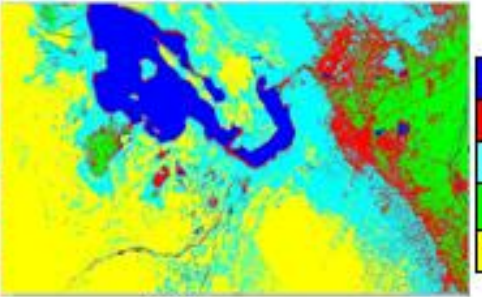

2015

Figure 2: The classified image using support vector machine.

Volume 6 Issue 7, July 2017 www.ijsr.net 


\section{International Journal of Science and Research (IJSR) \\ ISSN (Online): 2319-7064}

Index Copernicus Value (2015): 78.96 | Impact Factor (2015): 6.391

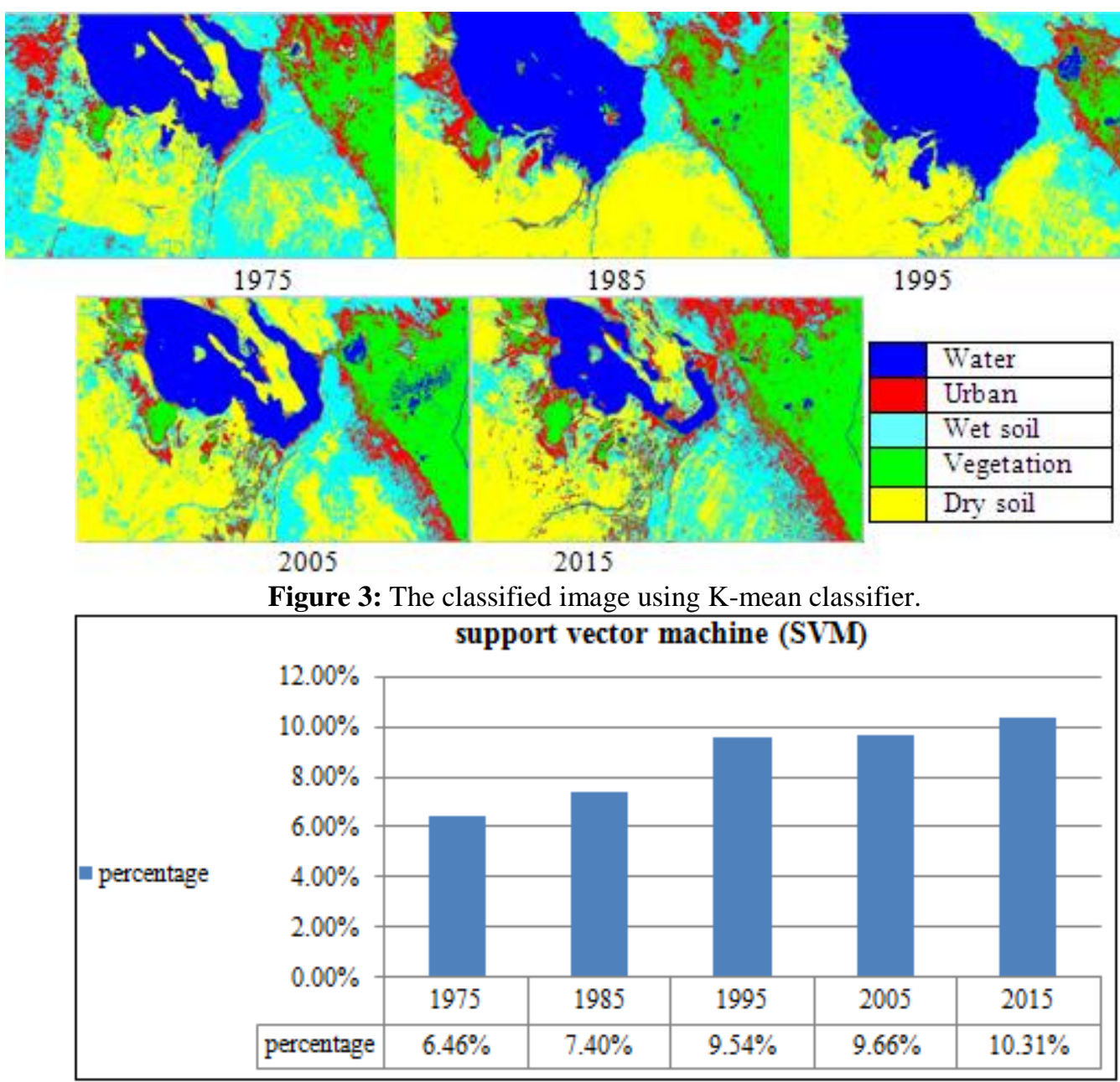

Figure 4: Thestatistical distribution of vegetation class using support vector machine classifier.

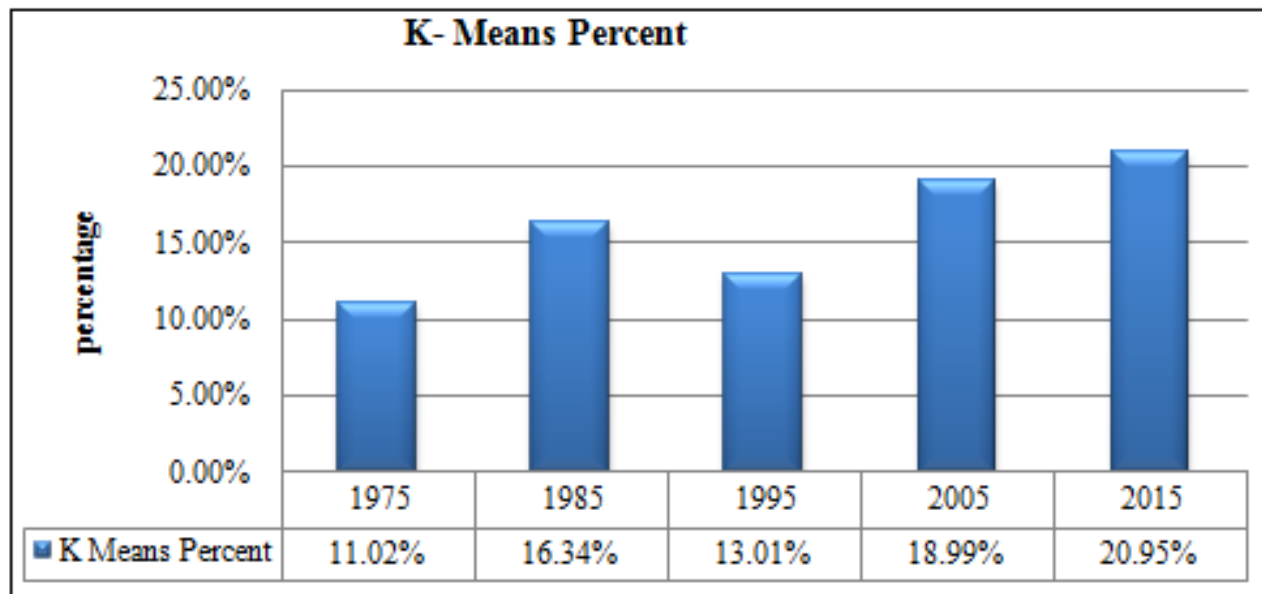

Figure 5: The statistical distribution of vegetation class usingK-mean classifier

\section{Target Detection}

The Target Detection Wizard guides you through the process to find targets in hyper spectral or multispectral images. The targets may be a material or mineral of interest or they may be man-made objects. In this paper two filters such as matching filter and Constrained Energy Minimization (CEM)have been adopted to perform the detection. In this filter the abundance of target was finding using a partial un-mixing algorithm. This technique maximizes the response of the known spectra and suppresses the response of the composite unknown background, therefore matching the known signature [10][11 ].The signature was represented by vegetation region and the results of applying this detection can be illustrated in figure (6) and figure (7) respectively, and the statistical total area and pixel count results of the vegetal regions can be shown in figures $(8) \&(9)$ respectivelly. The main step of perform this detection can be listed below:

Step one: input multi-spectral image for specified period such as image 1975.

Step two: apply atmosphere correction such radiometric correction to convert brightness value to reflectance value.

\section{Volume 6 Issue 7, July 2017 www.ijsr.net}




\section{International Journal of Science and Research (IJSR) \\ ISSN (Online): 2319-7064 \\ Index Copernicus Value (2015): 78.96 | Impact Factor (2015): 6.391}

Step three: using region of interest to select the object which has been detected in this research where vegetal cover has been selected..

Step four: convert the background to zero value.

Step five: apply Minimum Noise Fraction (MNF) transformation on the corrected image.
Step six: use matched filter and Constrained Energy Minimization (CEM) for target or object detection.

Step seven: apply clumbing filter with $(3 \times 3)$ window on final image.

Step eight: output result which have the target detection.

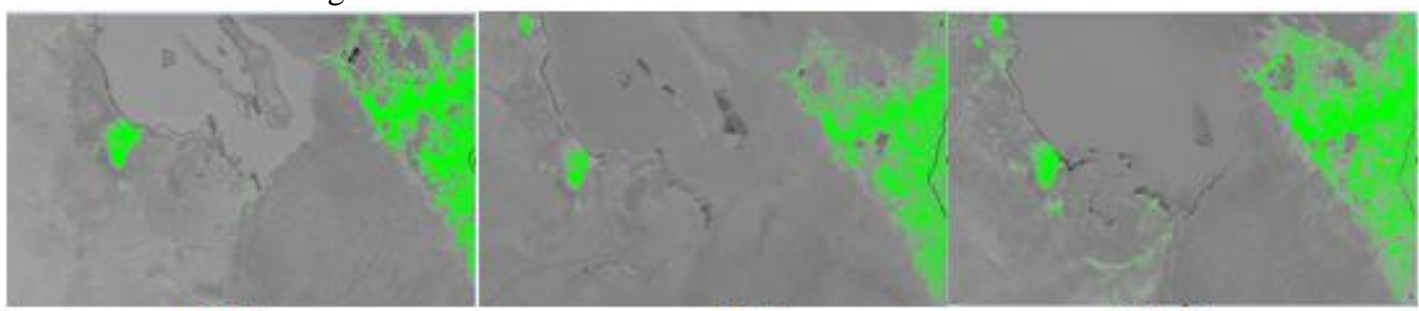

1975 1985 1995

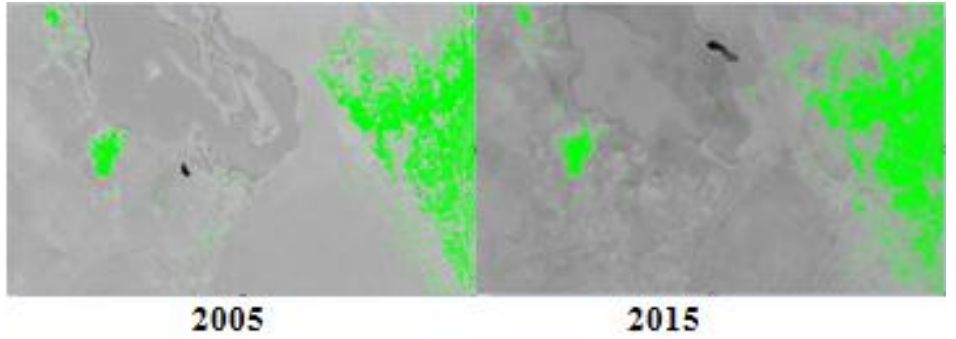

Figure 6: The results of applying the target detection using matching filter for different periods.

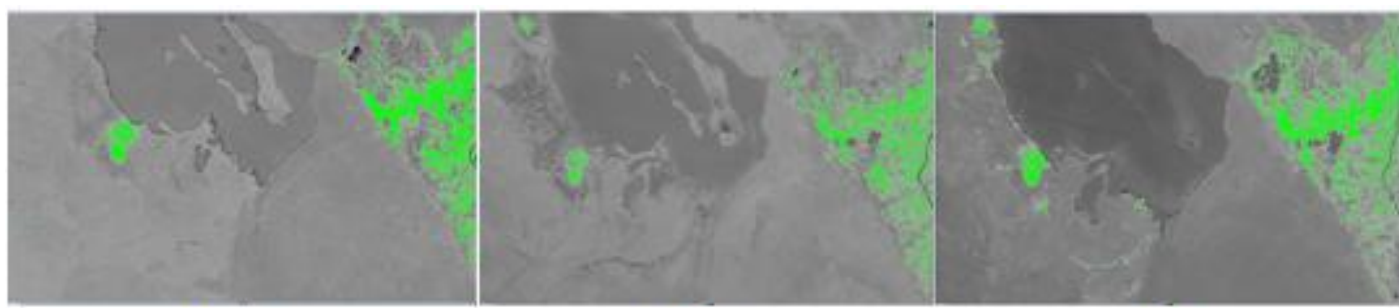

1975

1985

1995

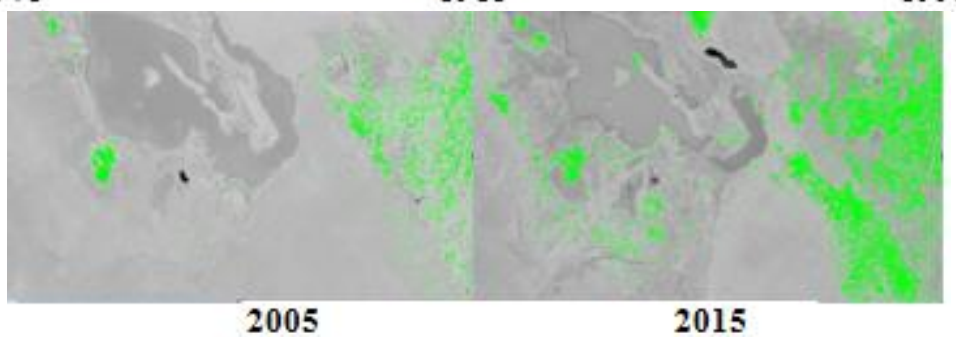

Figure 7: The results of applying the target detection using Constrained Energy Minimization (CEM).

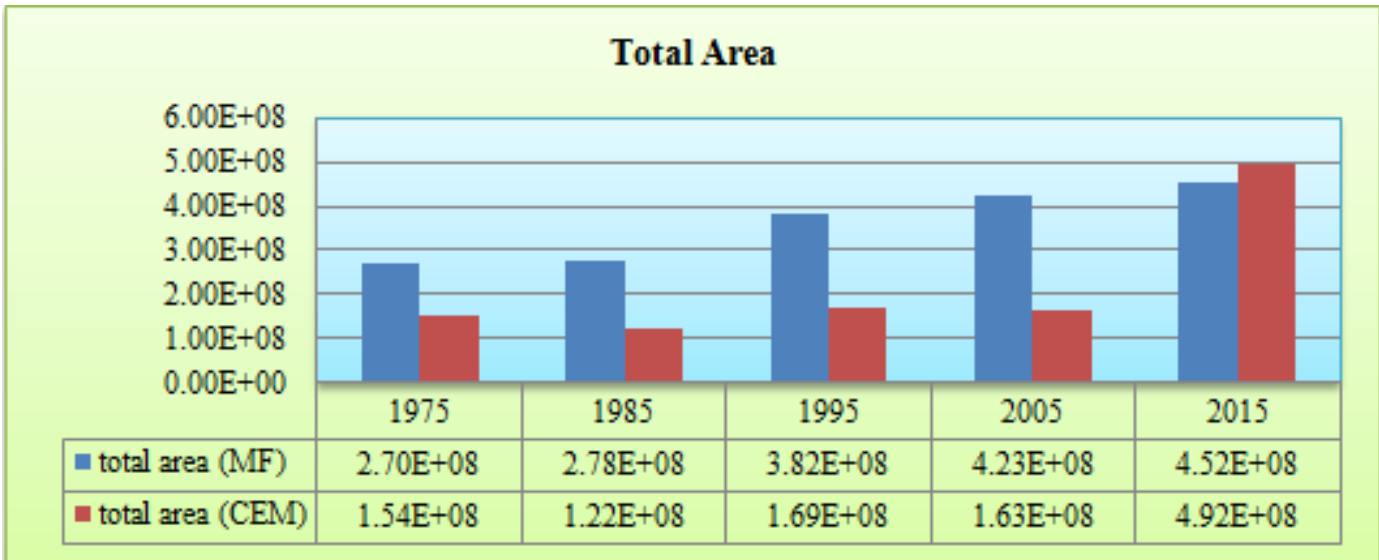

Figure 8: Shows the statistical total area results of the vegetal regions

Volume 6 Issue 7, July 2017 www.ijsr.net 
International Journal of Science and Research (IJSR)

ISSN (Online): 2319-7064

Index Copernicus Value (2015): 78.96 | Impact Factor (2015): 6.391

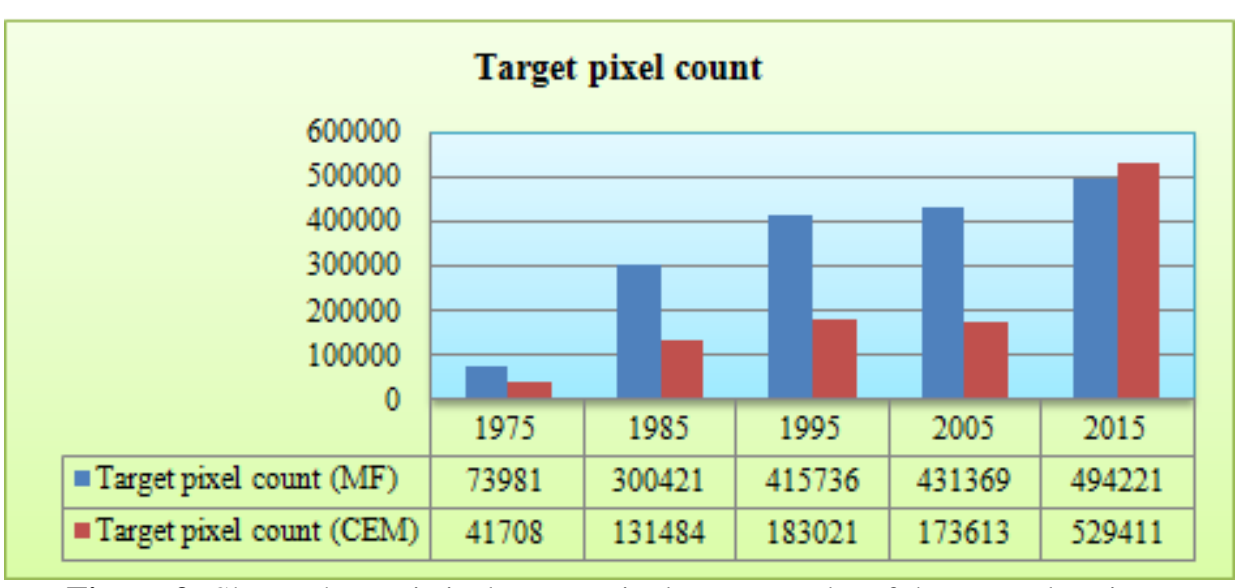

Figure 9: Shows the statistical Target pixel count results of the vegetal regions

\section{Discussion}

Change detection is a technology ascertaining the changes of land use and land cover features within a certain time interval. It provides the spatial distribution and information of features changes. This research interested with detects the vegetal cover of Karbala province using different remote sensing methods. The pre-processing includes radiometric, atmospheric corrections; geometrical rectification and image registration, all these correction have been applied on the gathered images, as well as gap restoration was applied on the defected image in 2005. Many monitoring techniques were employed to detect the vegetal cover of studied area, supervised classification has been applied and the results show increase of the vegetation region in 2015 compared with the past years (1975- 2005) and the expanding of vegetal cover have been done gradually from 1975 to 2015 period. This increase is indicating to interest of people in the cultivation of arid lands and increases the water share of the province. Target detection is consider to be very important stage of this research and give very reliability results to find and detect of the vegetal region and the results of these techniques were coincide with the results of supervised classification about the increase of vegetation region from 1975 to 2015 and the statistical distribution of this region can be shown in figures (4 and 5) respectively.

\section{References}

[1] Y. Setiawan and K. Yoshino, "change detection in landuse and land-cover dynamics at a regional scale from modis time-Series Imagery," ISPRS Ann. Photogramm. Remote Sens. Spat. Inf. Sci., vol. 1, no. 7, pp. 243-248, 2012.

[2] M. Jabalpur, "vegetation detection in multispectral remote sensing images: protective role-analysis of vegetation in 2004 Indian Ocean,” PDPM Indian Inst. Inf. Technol. Des. Manuf. Jabalpur, pp. 3-7, 2004.

[3] P. Taylor and A. Singh, "Review Article Digital change detection techniques using remotely-sensed data," Int. J. Remote Sens., vol. 10, no. 6, pp. 989-1003, 1989.

[4] J. Storey, P. Scaramuzza, G. Schmidt, and J. Barsi, "Landsat 7 Scan Line Corrector-Off Gap-Filled Product Gap-Filled Product Development," Pecora 16 "Global Priorities L. Remote Sens., vol. 16, pp. 23-27, 2005.

[5] L. S. D. and L. S. D. C. HUANG, "An assessment of support vector machines for land cover classié cation,"
Int. J. Remote Sens., vol. 23, no. 4, pp. 725-749, 2014.

[6] T. \& F. Group, "REMOTELY SENSED DATA CHARACTERIZATION , CLASSIFICATION , pp. 16 , 66, 176, 211.AND ACCURACIES," U. S. G. S. (USGS), Ed. 2016,

[7] T. \& F. Group, "CLASSIFICATION METHODS FOR REMOTELY SENSED DATA,” 2009, pp. 5-8, 11, 5460.

[8] T. \& F. Group, "REMOTELY SENSED DATA CHARACTERIZATION , CLASSIFICATION , AND ACCURACIES,” U. S. G. S. (USGS), Ed. 2016, pp. 16 , 66, 176, 211

[9] T. \& F. Group, "CLASSIFICATION METHODS FOR REMOTELY SENSED DATA,” 2009, pp. 5-8, 11, 5460.

[10] S. Buganim and S. R. Rotman, "Matched filters for multispectral point target detection," Proc. SPIE, vol. 6302, pp. 1-8, 2006.

[11] J. E. West, D. W. Messinger, E. J. Ientilucci, J. P. Kerekes, and J. R. Schott, "Matched filter stochastic background characterization for hyperspectral target detection," Proc. SPIE, vol. 5806, p. 2.

[12] LianruGao, Bin Yang, Qian Du and Bing Zhang, " Adjusted Spectral Matched Filter for Target Detection inHyperspectral Imagery", Remote Sens. 7, 6611-6634; doi:10.3390/rs70606611, 2015 